\title{
In-Situ Measurement of Fracture Strength of Solidifying Steel Shells to Predict Upper Limit of Casting Speed in Continuous Caster with Oscillating Mold
}

\author{
Mikio SUZUKI, Makoto SUZUKI, ${ }^{1)}$ Chonghee YU and Toshihiko EMI \\ Institute for Advanced Materials Processing, Tohoku University, Katahira, Aoba-ku, Sendai, Miyagi-ken, 980-77 Japan. \\ 1) Materials and Processing Research Center, NKK Corporation, Kokan-cho, Fukuyama, Hiroshima-ken, 721 Japan.
}

(Received on September 5, 1996; accepted in final form on November 12, 1996)

\begin{abstract}
Preventing crack formation of solidifying steel shell at increasing speed in continuous slab casting operation is a prerequisite to increase the ratio of hot charge rolling and hot direct rolling of cast slabs. Crack formation is influenced by mechanical properties of the steel shell near its solidus temperature. Thus, fracture strength of solidifying steel shells containing 0.004 to 0.70 mass $\% \mathrm{C}$ has been measured in-situ by using a method similar to "Submerged Split Chill Tensile (SSCT)" test by Ackermann, Kurz and Heinemann. The fracture strength at an early stage of solidification, when the shell thickness is 2 to $5 \mathrm{~mm}$, has been found to be 1 to $3.5 \mathrm{MPa}$ which is lower than that determined by conventional hot tensile tests, since the crack initiates at and propagates in interdendritic region in the shell in the in-situ SSCT test. Comparing the fracture strength of the shell with the frictional force at the shell/mold interface, upper limit of casting speed of slab caster is calculated to be around $8.5 \mathrm{~m} / \mathrm{min}$.
\end{abstract}

KEY WORDS: continuous casting; high temperature fracture strength; carbon steel; frictional force; in-situ measurement; solidifying shell.

\section{Introduction}

There has been a strong drive toward higher productivity and saving energy in the recent developments of continuous casting of steels. To make hot direct rolling, $\mathrm{HDR}$, into an industrial reality, the productivity of a caster should be increased to meet that of a hot strip mill. ${ }^{1}$ The caster productivity can be increased by a high speed casting, which has been materialized in thin slab casters $^{2)}$ operating at 4 to $6 \mathrm{~m} / \mathrm{min}$. However, a high speed casting results in a decreased mold flux consumption, causing higher frictional force at the shell $/ \mathrm{mold}$ interface. At a higher casting speed, thickness of the solidifying shell in mold decreases, shell temperature increases, and hence fracture strength of the shell decreases. Combination of the higher frictional force and the decreased shell strength makes it more difficult to prevent the formation of the surface cracks and breakouts of the shell at higher casting speeds.

For this reason, the fracture strength of solidifying steel shell was measured in the present study "in-situ" by a method similar to "Submerged Split Chill Tensile (SSCT)" test worked out by Ackermann et al. ${ }^{3)}$ Xia et $a l .{ }^{4)}$ and Hiebler et al. ${ }^{5}$ measured the fracture strength of various carbon steels with the SSCT test at a strain rate of $1 \times 10^{-2}$. However, shell growth may have taken place during the SSCT test made at such a low strain rate, making the observed fracture strength inaccurate. Present experiments were, therefore, carried out at a much higher strain rate to minimize the shell growth during the test. The fracture strength thus obtained was then compared with that by hot tensile test with in-situ melted and solidified test piece and a new temperature gradient tensile test. The new test developed by the authors ${ }^{6)}$ is a hot tensile test with temperature gradient applied to test piece to simulate the solidifying shell in mold. Frictional force at the shell/mold interface was calculated by a lubrication model which has also been developed by one of the authors. ${ }^{7)}$ Upper limit of casting speed was then estimated by comparing currently observed fracture strength of solidifying shells with the calculated frictional force.

\section{Experimental}

Experimental apparatus employed, which was essentially the same as SSCT test apparatus by Ackermann $e t$ al. ${ }^{3)}$ is schematically shown in Fig. 1. It consisted of a separable steel cap attached to a hydraulic ram and a fitting steel sleeve (10 $\mathrm{mm}$ in thickness) fixed to a support. This arrangement permitted to obtain a constant separation rate for the cap at an applied load, $F$, up to $30 \mathrm{kN}$. The separation force was measured with a load cell having a resolution of $\pm 30 \mathrm{~N}$. When the sleeve and cap were dipped into the melt, the solidifying shell was formed over the surface of the cap and sleeve. After a preset elapsed time, the shell was deformed at a separation rate, 


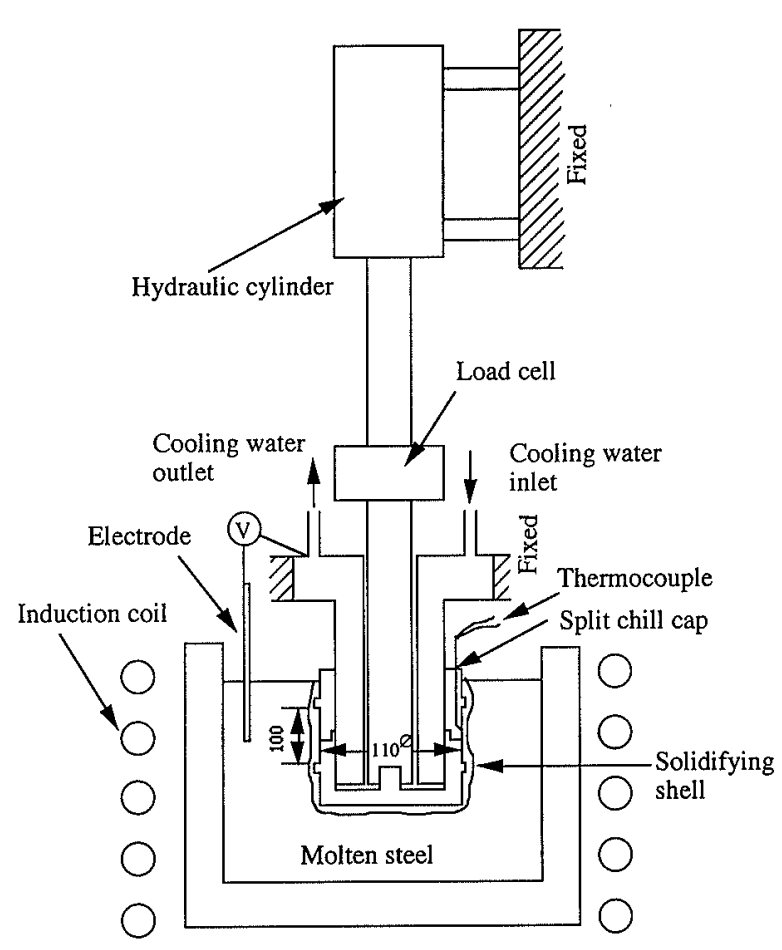

Fig. 1. Schematic diagram of experimental apparatus.

$V_{\mathrm{r}}$, in a direction parallel to the axis of the cylinder, and the corresponding load was measured. Only the straight vertical cylindrical portion having an initial height, $L_{0}$, of $100 \mathrm{~mm}$ and an outer diameter, $d_{0}$, of $110 \mathrm{~mm}$ was assumed to deform. The push down rate of the ram was adjusted to be $100 \mathrm{~mm} / \mathrm{s}$. Strain involved was less than $10 \%$, and the strain rate, $\varepsilon=V_{\mathrm{r}} / L_{0}$, was chosen close to $1 \mathrm{~s}^{-1}$. At the end of the test, the cap and sleeve with the shell were immediately taken out of the melt, and after cooling, the thickness of the shell was measured $15 \mathrm{~mm}$ above and below the separable position of the cap. An average value, $\delta_{\mathrm{s}}$, of the shell thickness was obtained from the observed shell thickness. A cross section area, $S$, of the shell was calculated with the average shell thickness as $S=\pi \delta_{\mathrm{s}}\left(d_{0}+\delta_{\mathrm{s}}\right)$. The temperature at the sleeve/shell interface was measured with a sheathed thermocouple of $1.6 \mathrm{~mm}$ in outer diameter which was embedded in the sleeve but its tip was placed about $0.5 \mathrm{~mm}$ above the sleeve surface at $15 \mathrm{~mm}$ above the separable position. The elapsed solidification time was 2 to $10 \mathrm{~s}$ before the tensile testing began, when a tensile force was applied for 0.02 to $0.04 \mathrm{~s}$. The load and the displacement were measured by a load cell and a laser distance meter. When the ram was pushed down, the load began to increase, reached a maximum, and then decreased rapidly as shown in Fig. 2. The load, $\Delta F$, applied to the shell was determined as the difference between the load, $F$ (load), at the tensile test and that, $F$ (idling), at the idling test in order to cancel the frictional force arising during the pushing down of the ram. The fracture strength, $\sigma_{\text {shell }}$, of the shell was calculated from $\Delta F$ and $S$ as $\sigma_{\text {shell }}=\Delta F / S$.

The chemical composition of the shell, dipping time, solidified shell thickness, observed interfacial temperature and related experimental conditions are given in Table 1.

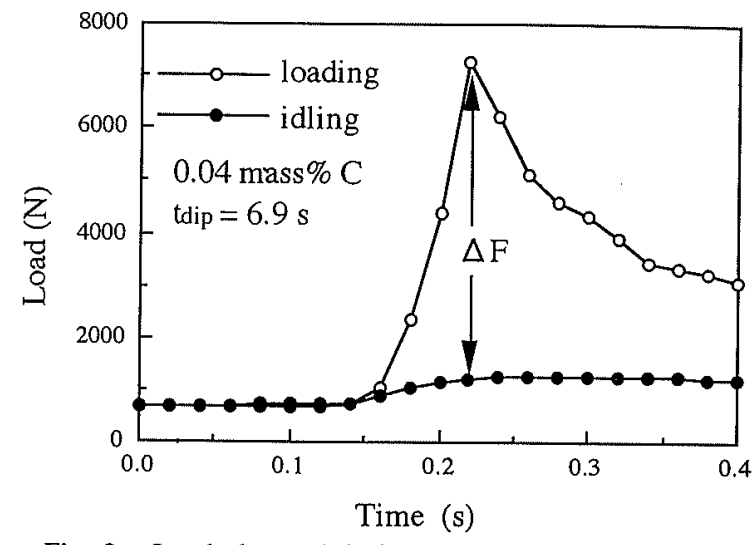

Fig. 2. Load observed during tensile test and idling test.

\section{Results and Discussion}

\subsection{Thickness and Temperature of Solidifying Shell}

Transverse cross section of the shell and the sleeve $15 \mathrm{~mm}$ above the separable position is shown in Fig. 3 for 0.04 and 0.12 mass $\%$ carbon steels. A uniform shell formed intact around the sleeve for the former whereas a shell of uneven thickness formed for the latter.

Even for such an early stage of solidification, the average shell thickness could be expressed in terms of the square root of solidification time as $\delta_{\mathrm{s}}=K \sqrt{t}+\beta$ where $K$ is a solidification constant and $\beta$ is a correction factor. The value of $K$ was determined from the observed $\delta_{\mathrm{s}}$ by a regression analysis, and is listed in Table 2 as a function of carbon content. Scattering of the data in the regression analysis is small except for 0.12 mass $\%$ carbon peritectic steel. Taylor ${ }^{8)}$ measured the solidification constant for the first few seconds of solidification by immersing a water cooled steel probe into steel melt and reported that the $K$ was $2.79\left(\mathrm{~mm} / \mathrm{s}^{0.5}\right)$ for mild steel. The equations in Table 2 are considered to be a good reference for the shell growth in the early stage of solidification of steel without mold flux with varying carbon content.

Difficulty in placing the tip of the thermocouple exactly $0.5 \mathrm{~mm}$ above the sleeve surface resulted in a large variation of the observed temperature of the shell at the shell/mold interface. As the measurement of shell thickness is considered to be more accurate than that of interfacial temperature in the present study, the calculated shell thickness, which corresponds to the thickness of the shell with the solid fraction of more than 0.7 at which solidifying shell begins to have tensile strength, ${ }^{9}$ was made consistent with the observed shell thickness by trimming the heat flux, $q$, as detailed in the following. This is similar to Xia et al., ${ }^{4)}$ who determined the interfacial temperature of solidifying shell by carrying out a numerical calculation with a finite difference method to make the calculated temperatures consistent with the temperatures measured at 4.5 and $13.5 \mathrm{~mm}$ away from the sleeve in solidifying shell. Temperatures in the solidifying shell and shell thickness were calculated by solving one dimensional heat conduction in cylindrical coordinates

$$
\rho \frac{\partial(C T)}{\partial t}=\frac{1}{r} \frac{1}{\partial r}\left[\lambda r \frac{\partial T}{\partial r}\right]
$$


Table 1. Chemical composition of steels and experimental conditions.

\begin{tabular}{|c|c|c|c|c|c|c|c|c|c|c|c|c|c|}
\hline Test & Chem & cal con & mposit & ion (mas & ss\%) & & $\mathrm{Tm}$ & $\overline{t_{d i p}}$ & $\overline{d_{s}}$ & 1 & $T_{i n t}^{\prime}$ & $\sigma_{\text {shell }}$ & 2.1 \\
\hline No. & C & $\mathrm{Si}$ & $\mathrm{Mn}$ & $P$ & $S$ & solAL & (K) & (s) & (mm) & (K) & $(\mathrm{K})$ & ( $\mathrm{MPa})$ & (K) \\
\hline PT-52 & 0.004 & 0.01 & 0.04 & 0.014 & 0.014 & 0.069 & 1863 & 2.91 & 2.47 & 1803 & 1722 & 1.37 & 1647 \\
\hline PT-54 & 0.004 & 0.06 & 0.07 & 0.013 & 0.013 & 0.061 & 1859 & 4.84 & 4.06 & 1802 & 1615 & 2.33 & 1607 \\
\hline PT-56 & 0.004 & 0.12 & 0.10 & 0.013 & 0.014 & 0.144 & 1859 & 6.78 & 5. 17 & 1801 & 1586 & 2. 42 & 1580 \\
\hline $\mathrm{PT}-17$ & 0.038 & 0.06 & 0.08 & 0.012 & 0.011 & 0.084 & 1854 & 4.84 & 4.06 & 1788 & $\mathrm{~F}$ & 2.04 & 1573 \\
\hline $\mathrm{PT}-18$ & 0.041 & 0.08 & 0.11 & 0.013 & 0.011 & 0.117 & 1849 & 4.92 & 4.42 & 1786 & 1608 & 1.55 & 1570 \\
\hline PT-19 & 0.038 & 0.14 & 0.15 & 0.013 & 0.011 & 0.039 & 1852 & 4.90 & 4.18 & 1787 & F & 2.21 & 1571 \\
\hline PT-20 & 0.036 & 0.05 & 0.01 & 0.012 & 0.014 & 0.106 & 1851 & 4.94 & 4.42 & 1789 & 1503 & 1.52 & 1569 \\
\hline PT-24 & 0.041 & 0.10 & 0.09 & 0.013 & 0.014 & 0.055 & 1849 & 4.86 & 4.40 & 1786 & 1503 & 2.13 & 1572 \\
\hline PT-26 & 0.042 & 0.15 & 0.17 & 0.013 & 0.014 & 0.125 & 1854 & 4.84 & 4. 32 & 1785 & 1523 & 2.78 & 1573 \\
\hline PT-60 & 0.040 & 0.05 & 0.08 & 0.014 & 0.013 & 0.013 & 1877 & 4.86 & 3.58 & 1787 & 1518 & 1.44 & 1572 \\
\hline PT-62 & 0.040 & 0.10 & 0.11 & 0.013 & 0.013 & 0.120 & 1833 & 4.93 & 4.26 & 1786 & 1513 & 1.80 & 1570 \\
\hline PT-64 & 0.037 & 0.16 & 0.01 & 0.014 & 0.013 & 0.140 & 1877 & 4.94 & 4.86 & 1787 & 1496 & 1.25 & 1569 \\
\hline PT-66 & 0.036 & 0.22 & 0.16 & 0.014 & 0.012 & 0.290 & 1853 & 4.89 & 4.11 & 1785 & 1433 & 2.84 & 1571 \\
\hline $\mathrm{PT}-75$ & 0.039 & 0.06 & 0.16 & 0.012 & 0.014 & 0.082 & 1851 & 2.89 & 2. 15 & 1787 & 1603 & 2.28 & 1622 \\
\hline PT - 76 & 0.041 & 0.08 & 0.13 & 0.012 & 0.013 & 0.090 & 1854 & 2.98 & 3. 10 & 1786 & 1613 & 1.35 & 1617 \\
\hline $\mathrm{PT}-77$ & 0.042 & 0.11 & 0.16 & 0.012 & 0.014 & 0.093 & 1849 & 4.91 & 3.50 & 1785 & 1703 & 1.84 & 1570 \\
\hline PT-78 & 0.042 & 0.10 & 0.13 & 0.012 & 0.013 & 0.133 & 1851 & 4.87 & 4.20 & 1785 & 1428 & 1.29 & 1572 \\
\hline PT-80 & 0.043 & 0.15 & 0.14 & 0.016 & 0.012 & 0.180 & 1855 & 6.93 & 6.50 & 1783 & 1588 & 1.45 & 1523 \\
\hline $\mathrm{PT}-82$ & 0.042 & 0.19 & 0.16 & 0.014 & 0.012 & 0.088 & 1850 & 8.87 & 7.50 & 1784 & 1433 & 2.40 & 1485 \\
\hline PT-83 & 0.040 & 0.22 & 0.18 & 0.012 & 0.013 & 0.105 & 1851 & 10.91 & 8.56 & 1784 & 1616 & 3. 16 & 1447 \\
\hline PT-84 & 0.042 & 0.23 & 0.18 & 0.011 & 0.011 & 0.152 & 1849 & 10.84 & 9.00 & 1784 & 1441 & 2.61 & 1448 \\
\hline $\mathrm{PT}-12$ & 0.114 & $0.09^{\circ}$ & 0.06 & 0.011 & 0.011 & 0.170 & 1844 & 4.85 & 3.42 & 1756 & $F$ & 2.57 & 1635 \\
\hline $\mathrm{PT}-13$ & 0.116 & 0.08 & 0.06 & 0.011 & 0.011 & 0.119 & 1844 & 6.95 & 3. 44 & 1756 & 1463 & 3.20 & 1616 \\
\hline PT-14 & 0.108 & 0.12 & 0.06 & 0.011 & 0.011 & 0.110 & 1842 & 8.89 & 4. 33 & 1758 & 1418 & 3.45 & 1600 \\
\hline $\mathrm{PT}-44$ & 0.116 & 0.20 & 0.14 & 0.013 & 0.014 & 0.117 & 1841 & 2.93 & 2.79 & 1753 & 1626 & .98 & 1651 \\
\hline PT-46 & 0.114 & 0.27 & 0.17 & 0.014 & 0.013 & 0.115 & 1842 & 4.84 & 3.39 & 1753 & 1468 & 1. 12 & 1635 \\
\hline PT-48 & 0.115 & 0.34 & 0.20 & 0.013 & 0.013 & 0.185 & 1843 & 6.86 & 4.73 & 1751 & 1424 & 1.34 & 1616 \\
\hline$P T-50$ & 0.119 & 0.40 & 0.23 & 0.013 & 0.013 & 0.201 & 1846 & 8.86 & 4.80 & 1748 & 1417 & 1.68 & 1600 \\
\hline PT-68 & 0.115 & 0.16 & 0.12 & 0.014 & 0.009 & 0.120 & 1843 & 4.95 & 3.23 & 1755 & 1603 & 1.76 & 1634 \\
\hline $\mathrm{PT}-70$ & 0.117 & 0.23 & 0.15 & 0.014 & 0.019 & 0.180 & 1840 & 5.02 & 3.60 & 1751 & 1593 & 1.01 & 1632 \\
\hline $\mathrm{PT}-72$ & 0.115 & 0.40 & 0.24 & 0.013 & 0.031 & 0.260 & 1842 & 5.00 & 4.28 & 1746 & 1673 & 1.03 & 1632 \\
\hline PT-74 & 0.115 & 0.44 & 0.26 & 0.013 & 0.050 & 0.290 & 1841 & 4.97 & 3.96 & 1742 & 1543 & 1.03 & 1634 \\
\hline $\mathrm{PT}-36$ & 0.358 & 0.14 & 0.13 & 0.012 & 0.014 & 0.134 & $1829^{\circ}$ & 2.93 & 4.07 & 1736 & $1575^{\circ}$ & 2.44 & 1598 \\
\hline PT-38 & 0.369 & 0.21 & 0.15 & 0.012 & 0.015 & 0.080 & 1828 & 4.88 & 4.74 & 1734 & 1465 & 1.97 & 1558 \\
\hline PT-40 & 0.361 & 0.29 & 0.19 & 0.012 & 0.014 & 0.235 & 1827 & 6.92 & 5.73 & 1732 & 1583 & 3.04 & 1533 \\
\hline PT-42 & 0.352 & 0.33 & 0.22 & 0.012 & 0.013 & 0.369 & 1831 & 8. 94 & 6.61 & 1731 & 1565 & 2.76 & 1510 \\
\hline $\mathrm{PT}-28$ & 0.655 & $\mathrm{tr}$ & 0.14 & 0.013 & 0.013 & 0.027 & 1791 & 2.93 & 3.70 & 1668 & 1553 & 1.36 & 1541 \\
\hline PT-30 & 0.666 & 0.33 & 0.20 & 0.011 & 0.013 & 0.140 & 1793 & 4.89 & 4.42 & 1660 & 1393 & 1.25 & 1496 \\
\hline PT-32 & 0.702 & 0.37 & 0.23 & 0.011 & 0.013 & 0.270 & 1795 & 6.91 & 6.34 & 1651 & 1523 & 1.58 & 1468 \\
\hline PT-34 & 0.723 & 0.42 & 0.26 & 0.011 & 0.013 & 0.410 & 1791 & 8.92 & 7. 48 & 1647 & 1408 & 2.44 & 1442 \\
\hline PT -10 & 0.707 & 0.48 & 0.29 & 0.011 & 0.013 & 0.490 & 1792 & 10.86 & 7. 35 & 1547 & 1543 & 1.91 & 1420 \\
\hline $\mathrm{T}-11$ & 0.701 & 0.52 & 0.32 & 0.011 & 0.012 & 0.560 & 1792 & 10.92 & 7.89 & 1548 & 1383 & 2.61 & 1419 \\
\hline
\end{tabular}

Initial and boundary conditions are taken as

$$
\begin{array}{lll}
\text { (i) } T=T_{\mathrm{M}}, \quad R_{0} \leqq r \leqq R_{\mathrm{L}}, & t=0 \\
\text { (ii) } \lambda(\partial T / \partial r)=-q, & r=\mathrm{R}_{0}, & t>0 \\
\text { (iii) } T=T_{\mathrm{M}}, & r=R_{\mathrm{L}}, & t>0
\end{array}
$$

where $\rho$ is density of steel $\left(\mathrm{g} / \mathrm{cm}^{3}\right), C$; specific heat capacity $(\mathrm{W} / \mathrm{g} / \mathrm{K}), \lambda$; thermal conductivity $(\mathrm{W} / \mathrm{cm} / \mathrm{K}), r$; distance $(\mathrm{cm})$ from the steel sleeve in radial direction, $R_{0}, R_{\mathrm{L}}$; radius (cm) of the outer surface of the sleeve and that some distance away from the sleeve surface in the melt, $T$ and $T_{\mathrm{M}}$, temperature (K) in solidifying shell and initial temperature, and $q$ is heat flux $\left(W / \mathrm{cm}^{2}\right)$ at the shell surface. In practice, Eqs. (1) through (2-3) were substituted by finite difference approximations. ${ }^{10)}$ The heat flux, $q$, was determined by solving the finite dif- ference approximations to make the calculated shell thickness agree with the observed ones by trial and error. The values of $q$ determined for each steel are shown in Fig. 4. Thermophysical properties such as $\rho, C$ and $\lambda$ used in this calculation were taken from literature, ${ }^{11)}$ and mesh size, $\Delta x$, of the shell and incremental time, $\Delta t$, are chosen to be $0.5 \mathrm{~mm}$ and $0.005 \mathrm{~s}$.

The interfacial temperature calculated with the finite difference method (FDM) and the calculated shell thickness for 0.04 carbon steel are shown in Fig. 5 together with the observed values. The calculated interfacial temperature is in reasonable agreement with the observed one. Consequently, the interfacial temperature calculated with FDM is taken as the interfacial temperature in the present study. The calculated temperature at the shell/ sleeve interface is summarized in Table 1. 


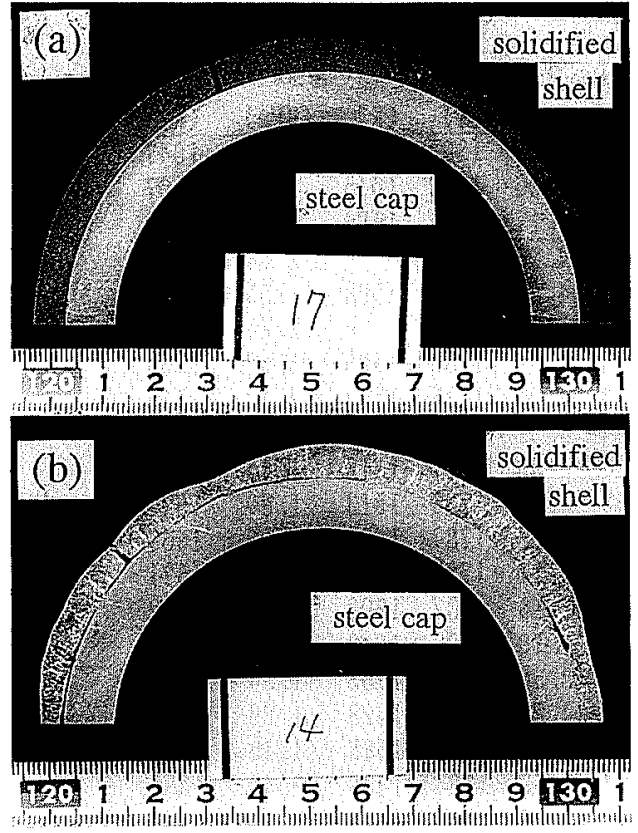

Fig. 3. Profile of transverse cross section of (a) 0.04 mass $\% \mathrm{C}$ steel shell at dipping time of $4.84 \mathrm{~s}$ and (b) $0.12 \mathrm{mass} \%$ C steel shell at $8.89 \mathrm{~s}$.

Table 2. Equations for solidifying shell thickness of steels derived by regression analysis of observed data.

\begin{tabular}{ccc}
\hline $\mathrm{C}$ (mass\%) & Shell thickness & $r^{2}$ \\
\hline 0.004 & $\delta_{\mathrm{s}}=2.79 \sqrt{t}-2.09$ & 0.95 \\
0.04 & $\delta_{\mathrm{s}}=3.44 \sqrt{t}-2.89$ & 0.93 \\
0.12 & $\delta_{\mathrm{s}}=2.20 \sqrt{t}-0.68$ & 0.68 \\
0.35 & $\delta_{\mathrm{s}}=2.74 \sqrt{t}-1.34$ & 0.97 \\
0.70 & $\delta_{\mathrm{s}}=2.79 \sqrt{t}-1.09$ & 0.97 \\
\hline
\end{tabular}

$\delta_{\mathrm{s}}:$ shell thickness $(\mathrm{mm}), t$ : time $(\mathrm{s}), r$ : correlation factor $(-)$

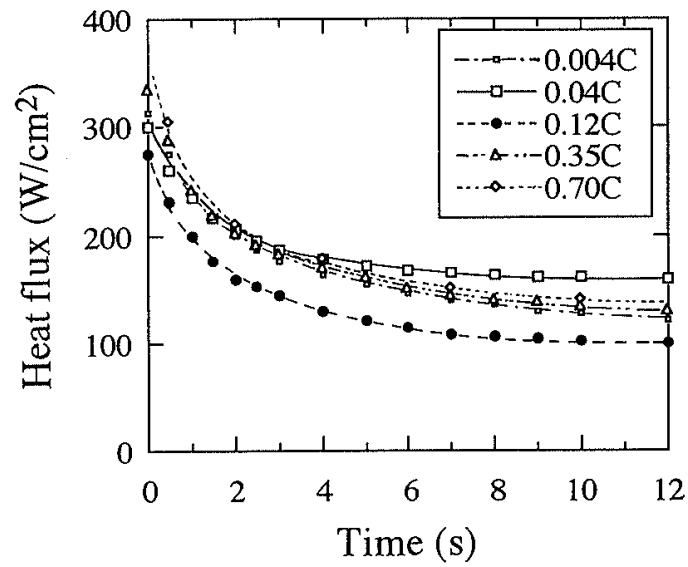

Fig. 4. Heat fluxes used for calculating temperatures in solidifying shell and melt of carbon steels.

\subsection{Fracture Strength of Solidifying Shells by SSCT Test}

3.2.1. Effect of Shell Thickness and Temperature on Fracture Strength

The fracture strength observed in the present study is plotted in Fig. 6 against the shell thickness. The fracture strength is in the range of 1 to $3.5 \mathrm{MPa}$ when the shell thickness is 2 to $5 \mathrm{~mm}$, but slightly increases with the shell thicker than $5 \mathrm{~mm}$.

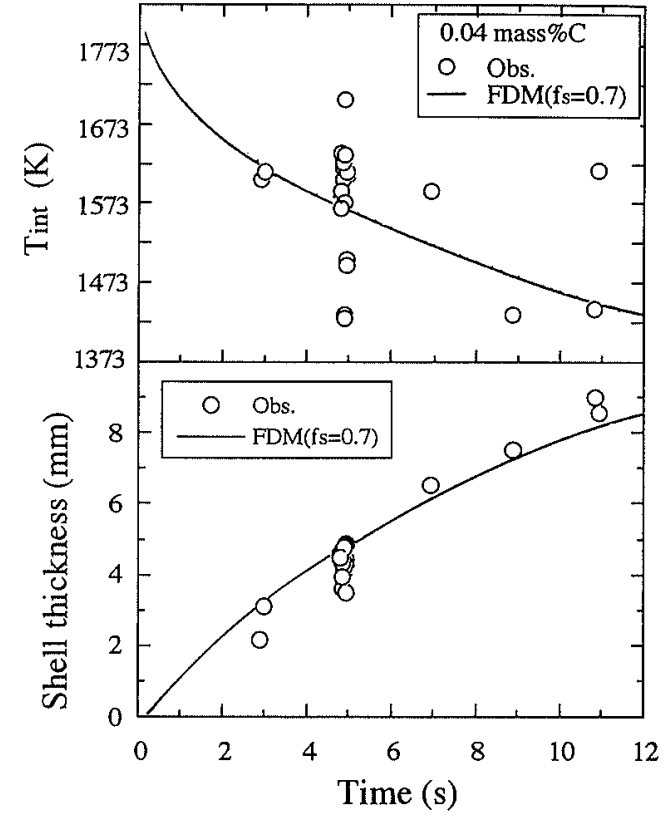

Fig. 5. Solidified shell thickness and temperature at the shell/ sleeve interface of (a) 0.04 mass \% carbon and (b) $0.12 \mathrm{mass} \%$ carbon steels as a function of dipping time.

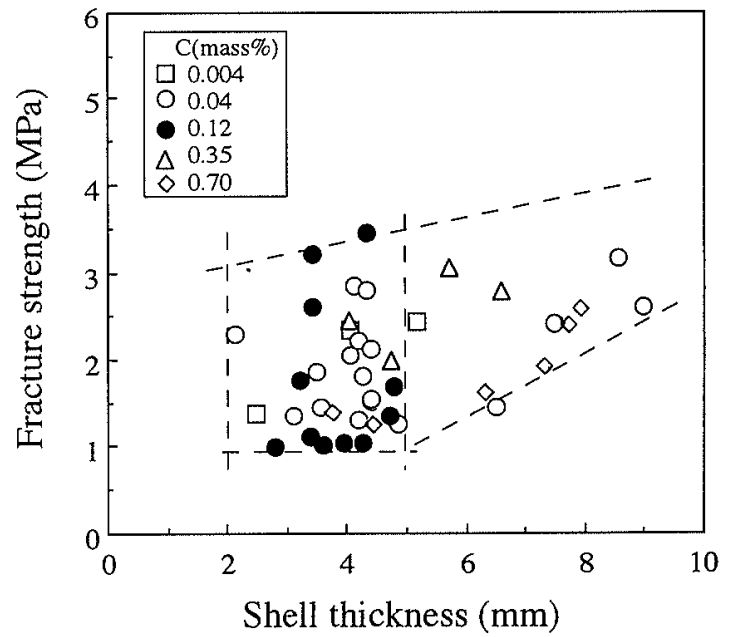

Fig. 6. Relation between fracture strength and thickness of solidified shell.

The fracture strength is shown in Fig. 7 as a function of the calculated interfacial temperature of the shell. The fracture strength increases with decreasing interfacial temperature. A line placed in this figure shows an equation for average fracture strength of 0.04 mass $\%$ carbon steel shell as derived from least square regression of the fracture strength data. This equation can be used to estimate the fracture strength of the shell at an early stage of solidification in predicting the upper limit of casting speed.

\subsubsection{Effect of $\mathrm{Mn} / \mathrm{S}$ Ratio on Fracture Strength}

The fracture strength of 0.04 mass $\%$ carbon steel at a dipping time of about $4.8 \mathrm{~s}$ is plotted against $\mathrm{Mn} / \mathrm{S}$ ratio in Fig. 8. The fracture strength decreases with decreasing $\mathrm{Mn} / \mathrm{S}$ ratio of the shell, similar tendency to the observation by Hiebler et al. ${ }^{5}$ for high carbon steels $(0.52$ 0.91 mass\%). Iron rich manganese sulfide, $(\mathrm{Fe}, \mathrm{Mn}) \mathrm{S}$, with low melting point forms in steels with low $\mathrm{Mn} / \mathrm{S}$ 


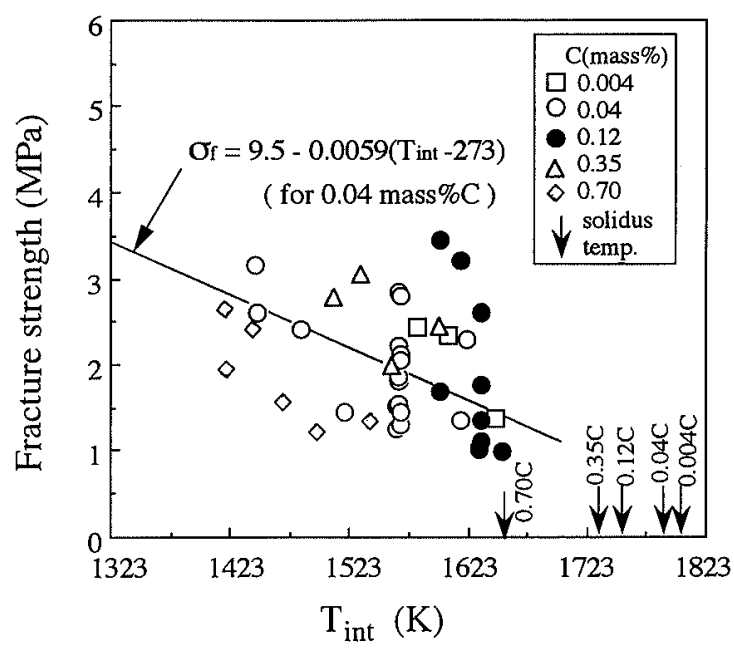

Fig. 7. Relation between fracture strength and calculated interfacial temperature of solidified shell.

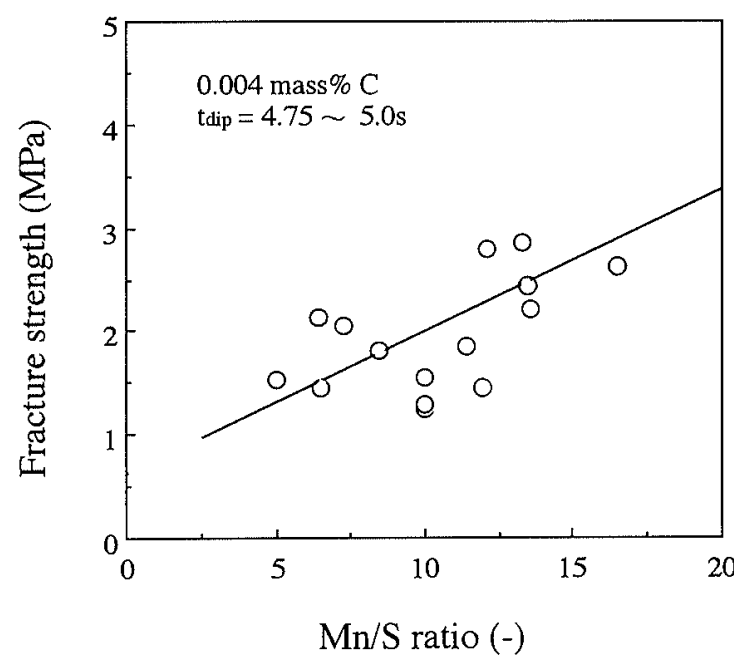

Fig. 8. Effect of $\mathrm{Mn} / \mathrm{S}$ ratio on fracture strength of solidified shell of 0.04 mass $\%$ carbon steel.

ratios, ${ }^{12)}$ and hence the shell exhibits partial melting, which is considered responsible for the decreased fracture strength of the shell with low $\mathrm{Mn} / \mathrm{S}$ ratios.

\subsection{Comparison of Fracture Strength Determined by SSCT Test, Hot Tensile Test under Temperature Gradient and in-Situ Melted and Solidified Test in Uniform Temperature Field}

It is difficult to compare the fracture strength of the shell with the tensile strength observed by a conventional hot tensile test in uniform temperature field, because the shell has temperature gradient. Then, a temperature to represent the fracture strength of the shell should be chosen. Yu et al ${ }^{6)}$ carried out a new hot tensile test in temperature gradient (hereafter temperature gradient, TG test) applied to test-piece. In this new method, one side of the test piece was heated to solidus temperature or to its zero strength temperature, ZST, and the other side was cooled and kept to a temperature similar to that of the solidifying shell surface in contact with a continuous casting mold via infiltrated mold flux film. They compared the tensile strength by the new tensile test carried out under temperature gradient with that by a conventional hot tensile test in uniform temperature field

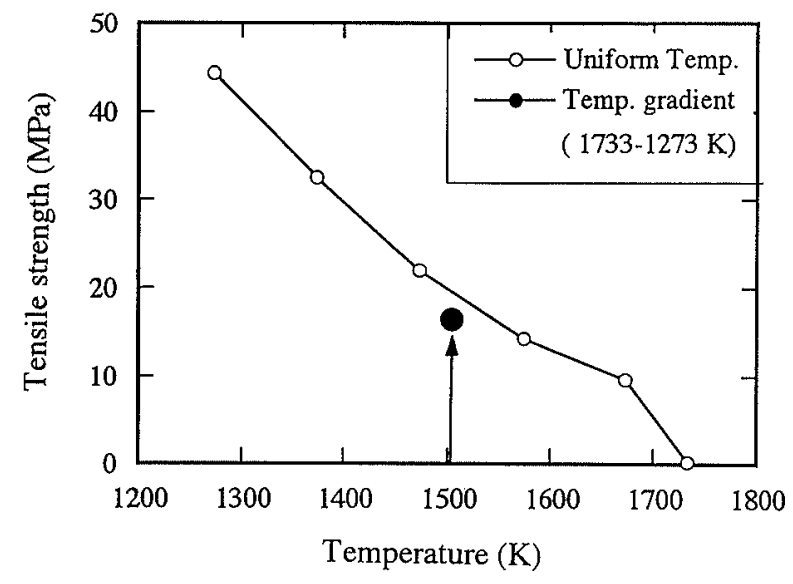

Fig. 9. Comparison of fracture strength by hot tensile test in uniform temperature field with that by temperature gradient test.
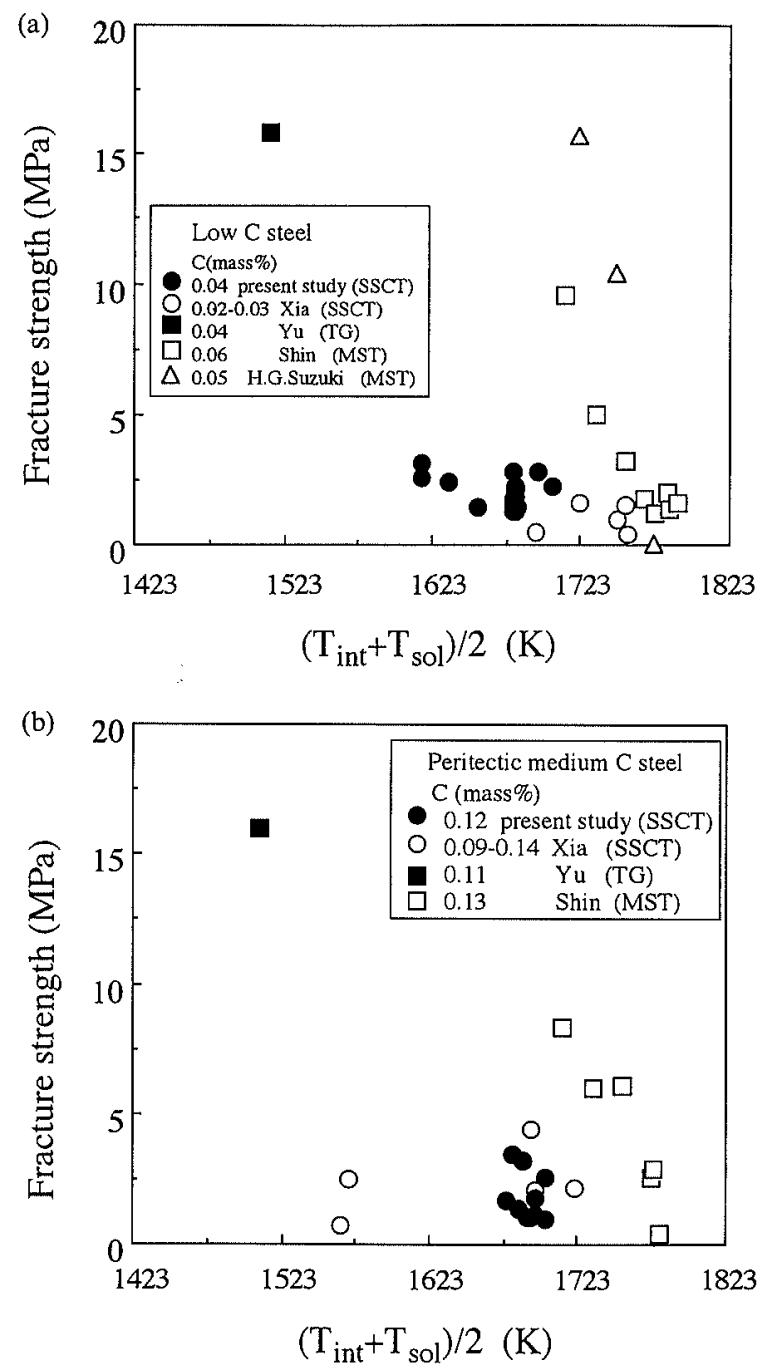

Fig. 10. Comparison of fracture strength of (a) 0.04 mass $\%$ carbon and (b) 0.12 mass \% carbon steels by SSCT test with that by in-situ melted and solidified uniform temperature hot tensile test and temperature gradient hot tensile test.

as shown in Fig. 9. Open circles denote the fracture strength determined by the conventional hot tensile test. The fracture strength by the TG test (hot side $1733 \mathrm{~K}$, cool side $1273 \mathrm{~K}$ ) is $17 \mathrm{MPa}$ as shown by a filled circle in Fig. 9. This value is close to the tensile strength at the 


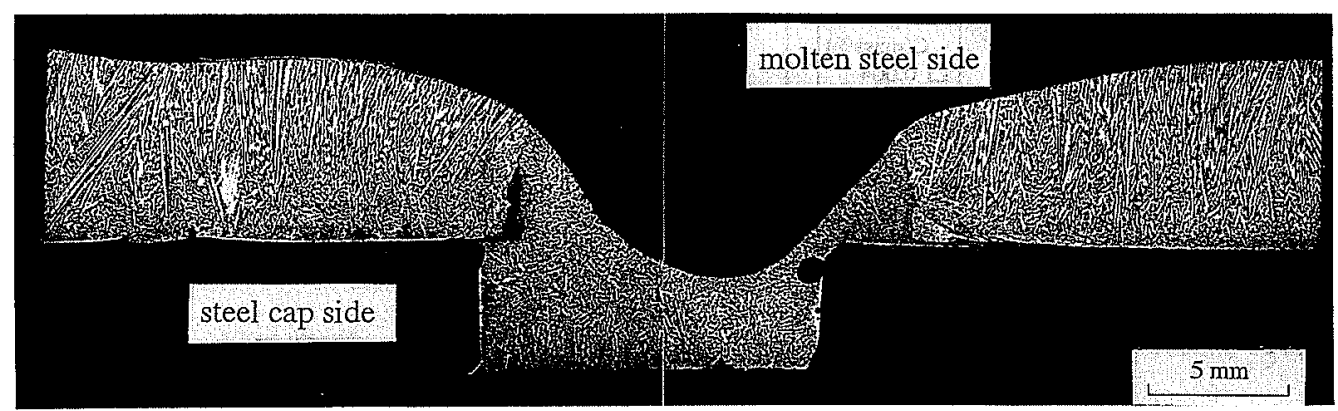

direction of ram push down

Fig. 11. Solidification structure of longitudinal cross section at fractured portion of 0.35 mass $\% \mathrm{C}$ steel shell $\left(t_{\mathrm{dip}}=8.84 \mathrm{~s}\right)$.

averaged temperature, $1503 \mathrm{~K}$, of the two sides of the test piece in the conventional hot tensile test. To compare the tensile strength by the TG test and the fracture strength by the present SSCT test of solidifying shell with the tensile strength by in-situ melted and solidified tensile tests (hereafter in-situ MST test) after Shin et al. ${ }^{8)}$ and H. G. Suzuki et al., ${ }^{13)}$ an average temperature, $T_{\mathrm{av}}=$ $\left(T_{\text {sol }}+T_{\text {int }}\right) / 2$ for SSCT test or $T_{\text {av }}=\left(\mathrm{ZST}+T_{\text {cool }}\right) / 2$ for the TG test, is defined to represent the shell temperature. The fracture strength for low carbon steel and peritectic medium carbon steel by the present SSCT test is plotted against $T_{\mathrm{av}}$ in Figs. 10(a) and 10(b) together with that by previous SSCT test after Xia et al. ${ }^{4)}$ The strain rate was $1 \times 10^{-2} \mathrm{~s}^{-1}$ for the in-situ MST test by Shin et al., $5 \mathrm{~s}^{-1}$ for the same by H. G. Suzuki et al., ${ }^{13)} 1 \mathrm{~s}^{-1}$ for the TG test by $\mathrm{Yu}$ et $\mathrm{al}$, and $4 \times 10^{-2}-2 \times 10^{-3} \mathrm{~s}^{-1}$ for the previous SSCT test by Xia et al. ${ }^{4)}$ The fracture strength by the present and the previous SSCT test slightly increases with decreasing shell temperature, and agrees with each other, i.e., 1-3.5 MPa just below their solidus temperatures, irrespective of the strain rate. On the other hand, the tensile strength by in-situ MST test after Shin et $a l^{8)}$ and H. G. Suzuki et al. $^{13)}$ increases steeply with deceasing temperature. The tensile strength generally depends on the strain rate. The data by $\mathrm{H}$. G. Suzuki et al. at higher strain rate seem to be slightly higher than those observed at low strain rate by Shin et al. as shown in Fig. 10(a), whereas the fracture strength by Yu et al. ${ }^{6}$ ) under the temperature gradient is close to that extrapolated from the relation between the tensile strength and temperature by in-situ MST test in the uniform temperature field.

Solidification structure at the fractured portion of 0.35 mass $\% \mathrm{C}$ steel shell at the dipping time of $8.94 \mathrm{~s}$ is shown in Fig. 11. The fracture initiated at and propagated in the interdendritic region. Penetration of the melt is observed into a crevice caused by the fracture of the shell. In the SSCT test, columnar dendrites were directed perpendicular to the tensile direction and cracks propagated in interdendritic region, whereas in the insitu MST test the dendrites were grown parallel to the tensile direction.

The fracture strength of steels tested in the present study is plotted against the calculated interfacial temperature in Fig. 12 together with the previous SSCT data by Xia et $a l .{ }^{4)}$ The fracture strength of medium

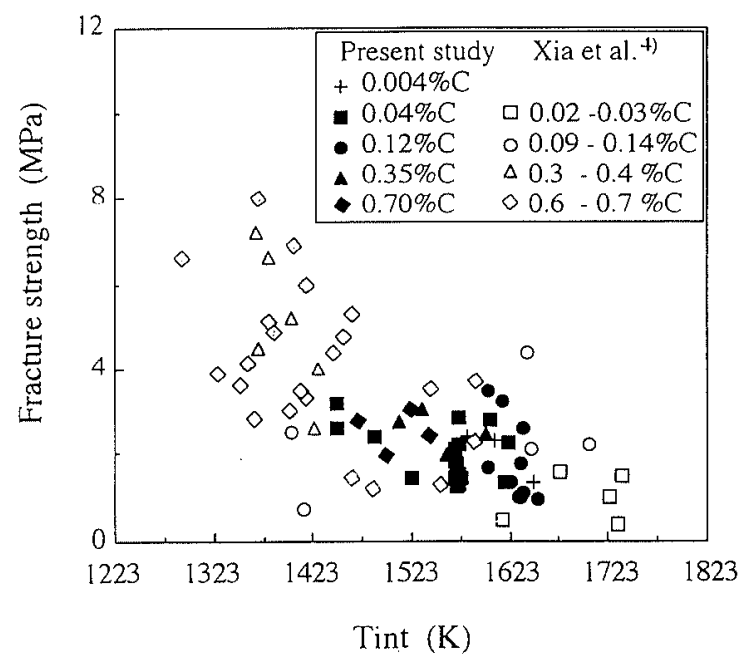

Fig. 12. Fracture strength of carbon steels by present SSCT test compared with that by previous SSCT test.

carbon and high carbon steels at austenitic $(\gamma)$ temperature is larger than that of ultra low carbon and low carbon steels in $\delta$-ferrite temperature, as Xia et al. ${ }^{4)}$ pointed out. However, for peritectic medium carbon steel $(0.12$ mass $\% \mathrm{C})$ the solidifying shell of which consists of $\delta$-ferrite and $\gamma$ phases, large scatter of the fracture strength is observed. The large scatter is considered due to the uneven shell formation shown in Fig. 3. For the time being, therefore, it is not clear whether or not the fracture strength of peritectic medium carbon steel shell is larger than that of low carbon and ultra low carbon steels.

\subsection{Prediction of the Upper Limit of the Casting Speed}

M. Suzuki et al. ${ }^{14)}$ estimated the upper limit of casting speed of a continuous caster with oscillating mold by comparing the frictional force at the shell/mold interface with limited data of the fracture strength of low carbon steel as determined by a hot tensile test in uniform temperature field. The upper limit of casting speed will be predicted in the following by using the same method but with the more reliable fracture strength of shell obtained in the present study.

In a continuous casting mold, a flux film infiltrates the shell/mold interface. The flux film near the shell is in liquid state while the rest is in solid state. Frictional force arises within the liquid film from the motion of the mold relative to the shell. Frictional force of this kind has been 
repotrted to be nearly equal to shear force of liquid flux film at the shell/mold interface over the whole mold surface when casting speed is in excess of $2.0 \mathrm{~m} / \mathrm{min} .^{14}$ ) The frictional force, $F_{1}$, resulting from the viscosity of the liquid film may be expressed by

$$
F_{\mathrm{l}}=\eta\left(V_{\mathrm{m}}-V_{\mathrm{c}}\right) / d_{1}
$$

where $\eta$ is the viscosity of liquid flux film $(\mathrm{g} / \mathrm{cm} \mathrm{s}), d_{1}$; the thickness of flux film $(\mathrm{cm}), V_{\mathrm{m}}$, the mold speed $(\mathrm{cm} / \mathrm{s})$, and $V_{\mathrm{c}}$ is the casting speed $(\mathrm{cm} / \mathrm{s})$. The viscosity of the liquid flux film can be calculated within a narrow span of temperature from an Arrhenius type expression, $\eta=$ $A \exp \left(-Q / R T_{\mathrm{fm}}\right)$, where $Q$ is the activation energy, $R$; the gas constant, $T_{\mathrm{fm}}$, the temperature of the liquid flux film, and $A$ is a constant. The values of $A, Q$ and $T_{\mathrm{fm}}$ have been determined experimentally by one of the authors. ${ }^{14)}$

The temperature of the liquid flux film can be calculated by assuming the steady state of heat transfer through the solidifying steel shell to the mold wall. Thermal resistance at the shell/flux film boundary is assumed to be zero. Then, the temperature of the liquid flux film in contact to the shell becomes equal to the interfacial temperature, $T_{\text {int }}$, of the shell, which can be calculated by

$$
T_{\text {int }}=T_{\text {liq }}-q_{\mathrm{h}} \delta_{\mathrm{s}} / \lambda
$$

where $q_{\mathrm{h}}$ is the heat flux $\left(\mathrm{W} / \mathrm{cm}^{2}\right)$ and $\lambda$ is the thermal conductivity $(\mathrm{W} / \mathrm{cm} / \mathrm{K})$ of the shell. The viscosity of the liquid flux film is taken to be that at the average temperature, $T_{\mathrm{fm}}=\left(T_{\mathrm{int}}+T_{\text {cry }}\right) / 2$, of the liquid flux film, where $T_{\text {cry }}$ is the crystallization temperature $(\mathrm{K})$ of the flux. The thickness of the liquid flux film is calculated from the rate of the consumption of the flux in actual caster operation as

$$
d_{1}=Q_{\mathrm{f}} / \rho_{\mathrm{f}}
$$

and

$$
Q_{\mathrm{f}}=q_{\mathrm{p}} \cdot f / V_{\mathrm{C}}
$$

where $Q_{\mathrm{f}}$ is the rate of the consumption $\left(\mathrm{g} / \mathrm{cm}^{2}\right)$ of the flux per unit area of the shell, $\rho_{\mathrm{f}}$; the density $\left(\mathrm{g} / \mathrm{cm}^{3}\right)$ of the flux, $q_{\mathrm{p}}$ equals $Q_{\mathrm{f}}$ per unit area per one cycle $\left(\mathrm{g} / \mathrm{cm}^{2} /\right.$ cycle), and $f$ is the frequency of mold oscillation (cycle/min). It is known from experiments that $q_{\mathrm{f}}$ is proportional to the positive strip time in one oscillation cycle, i.e., $q_{\mathrm{p}}=a t_{\mathrm{p}}+b$, where $t_{\mathrm{p}}$ is the positive strip time(s),

Table 3. Values used for calculating frictional force at shell/ mold interface.

\footnotetext{
$q_{\mathrm{p}}=0.12 t_{\mathrm{p}}+0.008$

$\log \eta=8326 / T_{\mathrm{mf}}-5.28\left(T_{\mathrm{mf}} \geq 1323 \mathrm{~K}\right)$

$\log \eta=21018 / T_{\mathrm{mf}}-14.88\left(1223 \leq T_{\mathrm{mf}}<1323 \mathrm{~K}\right)$

$\delta_{\mathrm{s}}=2.84 \sqrt{t}$

$q_{\mathrm{n}}$ : heat flux $\left(\mathrm{W} / \mathrm{cm}^{2}\right)$

$q_{\mathrm{p}}$ : rate of mold flux consumption $\left(\mathrm{g} / \mathrm{cm}^{2}\right.$ cycle)

$\eta$ : viscosity of mold flux (poise)

$\delta_{\mathrm{s}}$ : shell thickness $(\mathrm{mm})$

$t$ : time (s)

$t_{\mathrm{p}}$ : positive strip time (s)

$T_{\mathrm{mf}}:$ temperature of flux film $(\mathrm{K})$
}

$q_{\mathrm{h}}=257.5-12.28 t+0.8355 t^{2}-0.0349 t^{3}+0.00005 t^{4}(0 \leq t \leq 30.0)$ and $a$ and $b$ are experimental constants. Values ${ }^{14)}$ used for the calculation of the frictional forces are listed in Table 3.

The upper limit of the casting speed of a caster with an oscillating mold can be predicted by comparing the fracture strength of the shell with the tensile stress due to the frictional force at the shell/mold interface. The comparison is carried out for sinusoidal mode of oscillation. If the frictional force imposed on the shell exceeds the fracture strength, the shell will fracture, leading to the breakout of the shell in an extreme case. The tensile stress, $\sigma_{\mathrm{f}}$, imposed on the shell at a distance, $z$, from the meniscus is calculated as

$$
\sigma_{\mathrm{f}}=\left(\frac{1}{\delta_{\mathrm{s}}}\right) \int_{0}^{z} F_{1} d z
$$

The frictional force for the upward motion of the mold during one oscillation cycle imposes a tension on the shell. The tensile stress due to the frictional force becomes largest when the speed of the upward motion of the mold reaches its maximum. The largest frictional force, $F_{1}^{\max }$, for 0.04 mass $\%$ carbon steel is calculated at the change of casting speed. The fracture strength is considered to be influenced by unevenness of shell thickness and temperature, and microsegregation in interdendritic region. However, the influence of these factors on the fracture strength could not be made clear quantitatively in the present study. Accordingly, the equation for estimating the average fracture strength from the interfacial tempetature was determined as the line shown in Fig. 7. The average fracture strength is obtained from this line at corresponding interfacial temperature. The largest tensile stress calculated by Eq. (7) is plotted against the fracture strength of the shell in Fig. 13 as a function of the distance from the meniscus. The tensile stress due to the frictional force and the interfacial temperature increases whereas the fracture strength decreases with increasing casting speed. The tensile stress $25 \mathrm{~mm}$ below the meniscus is smaller than that $50-100 \mathrm{~mm}$ below. The tensile stress exceeds the fracture strength $50-100 \mathrm{~mm}$ below the meniscus when the casting speed becomes higher than about $8.5 \mathrm{~m} / \mathrm{min}$, indicating that the shell may fracture and result in a breakout beyond this casting speed. Thus, under the present conditions, the upper limit of the casting speed in continuous casting

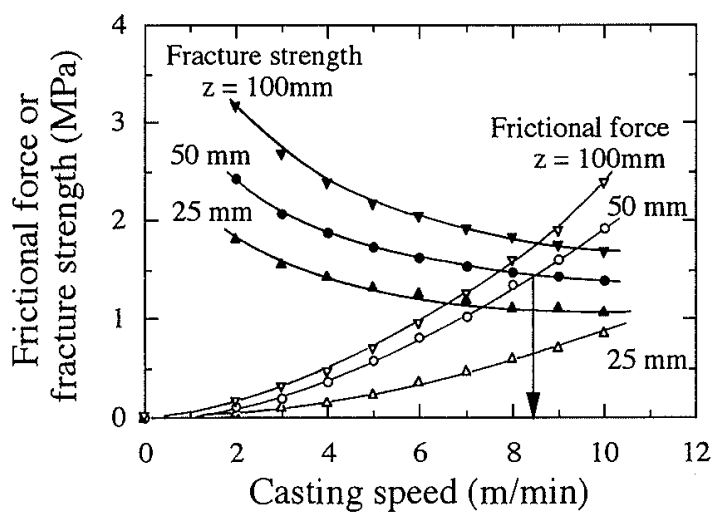

Fig. 13. Comparison of fracture strength of solidifying shell with frictional force at shell/mold interface below the meniscus. 
of steels with sinusoidally oscillating mold is predicted to be $8.5 \mathrm{~m} / \mathrm{min}$, about $140 \%$ of what has been realized in current thin slab casting operations.

\section{Conclusions}

The fracture strength of solidifying shell of carbon steels $(0.004$ to 0.70 mass $\%$ C) has been determined by "in-situ" measurement similar to Ackermann, Kurz and Heinemann's "Submerged Split Chill Tensile (SSCT)" test. Also, the frictional force between the shell and the mold wall has been calculated after previously developed lubrication model, and compared with the fracture strength. The results obtained are:

(1) growth rate of solidifying shell thickness without mold flux is proportional to the square root of time even at a very early period of the shell formation. Constants involved in the square root equations are determined for different carbon contents. Also, the shell growth of 0.12 mass $\% \mathrm{C}$ steel is inhomogeneous even in the beginning of the solidification.

(2) the fracture strength at a very early stage of solidification of the shell thickness of 2 to $5 \mathrm{~mm}$ is determined to be 1 to $3.5 \mathrm{MPa}$.

(3) the fracture strength of the solidifying shell determined by the SSCT test below the solidus temperature is lower and increases less with elapsing time and decreasing interfacial temperature than that by in-situ melted and solidified hot tensile tests, possibly due to the difference in the growth direction of dendrites (SSCT test perpendicular to whereas in-situ MST tests parallel to tensile direction).

(4) the upper limit of the casting speed of a caster with sinusoidally oscillating mold is estimated by com- paring the fracture strength with the frictional force to be about $8.5 \mathrm{~m} / \mathrm{min}$.

\section{Acknowledgments}

The authors would like to thank Materials and Processing Research Center of NKK for their assistance to carry out "in-situ" measurement test of fracture strength of solidifying steel shells.

\section{REFERENCES}

1) T. Koyano, Y. Shiratani, S. Uchida, T. Wada and T. Masaoka: Tetsu-to-Hagané, 72 (1986), 276.

2) F. K. Iverson and K. Busse: Stahl Eisen, 111 (1991), 37MST test.

3) P. Ackermann, W. Kurz and W. Heinemann: Mater. Sci. Eng., 75 (1985), 79.

4) Xia Guangmin, J. Zirngast, H. Hiebler and M. M. Wolf: Proc. Conf. on Continuous Casting of Steel in Developing Countries, The Chinese Soc. for Met, Beijing, (1993), 200.

5) H. Hiebler, J. Zirngast, Ch. Bernhard and M. M. Wolf: Steelmaking Conf. Proc., 77 (1994), 405.

6) C. H. Yu, H. Shibata, M. Suzuki and T. Emi: Bull. Inst. Adv. Mater. Processing, Tohoku Univ., 51 (1995), 50.

7) M. Suzuki, H. Mizukami, T. Kitagawa, K. Kawakami, S. Uchida and Y. Komatsu: ISIJ Int., 31 (1991), 254.

8) C. R. Taylor: Metall. Trans., B, 6B (1975), 359.

9) G. Shin, T. Kajitani, T. Suzuki and T. Umeda: Tetsu-to-Hagané, 78 (1992), 587.

10) Special Report No.11, Heat Transfer Experiment and Calculation Method in Reheating Furnace for Continuously Cast Strand in Japanese, ISIJ, Tokyo, (1975), 74.

11) Tekko-Binran (Handbook of Iron and Steel in Japanese ed. by ISIJ), Vol. 1, 3rd Ed., Maruzen, Tokyo, (1981), 79.

12) G. S. Mann and I. H. Van Vlack: Metall. Trans. B, 7B (1976), 469.

13) H. G. Suzuki, S. Nishimura and Y. Nakamura: Trans. Iron Steel Inst. Jpn., 24 (1984), 54.

14) M. Suzuki, S. Miyahara, T. Kitagawa, S. Uchida, T. Mori and K. Okimoto: Tetsu-to-Hagané, 78 (1992), 113. 